Artigo Original

\title{
Efeitos do fenobarbital sobre o reparo e a biomecânica de ossos em ratos Wi star*
}

\author{
Effects of phenobarbital on bone repair and biomechanics in rats \\ Efectos del fenobarbital sobre la reparación y la biomecánica de buesos en ratas Wistar
}

\section{RESUMO}

Vander Alves Pereira ${ }^{1}$, Mara Aparecida de Ávila ${ }^{1}$, Yolanda Cristina de Souza Loyola ${ }^{2}$, Wilson Romero Nakagaki ${ }^{3}$, José Ângelo Camilli ${ }^{3}$, José Antônio Dias Garcia ${ }^{2}$, Evelise Aline Soares ${ }^{2}$

Objetivo: Avaliar os efeitos morfológicos do tratamento com fenobarbital, sobre a neoformação óssea e sobre a biomecânica óssea do osso de ratos Wistar. Métodos: Foram utilizados dez ratos divididos em dois grupos: controle (CT) e fenobarbital (FE). O grupo FE recebeu doses diárias de fenobarbital $0,035 \mathrm{ml} / \mathrm{kg}$ via intramuscular, por 60 dias. O grupo CT recebeu a mesma dose e via de administração de solução fisiológica $0,9 \%$. Após 30 dias, foi realizada uma falha óssea no osso parietal e implantada a hidroxiapatita porosa (HAP) em cavidades nas tíbias. Após as cirurgias, manteve os respectivos protocolos até completar 60 dias e serem eutanasiados, sendo os ossos coletados.Resultados: $\mathrm{O}$ volume de osso formado ao redor HAP na falha parietal e os achados biomecânicos foram menores nos animais do grupo FE em relação ao CT. Conclusão: O uso prolongado do fenobarbital interfere no reparo ósseo após lesões, diminui a osseointegração de implantes de HAP e torna os ossos menos resistentes.

Descritores: Durapatita; Osseointegração; Osteogênese; Fenobarbital/efeitos adversos; Osso e ossos/efeitos de drogas

\begin{abstract}
Objective: To evaluate the morphological effects of phenobarbital treatment on new bone formation and on bone marrow biomechanics in Wistar rats. Methods: We used ten rats that were divided into two groups: control (CT) and phenobarbital (FE). The FE group received daily doses of phenobarbital $0.035 \mathrm{ml} / \mathrm{kg}$ intramuscularly for 60 days. The CT group received the same dose and route of administration of $0.9 \%$ saline solution. After 30 days, we introduced a bone defect in the parietal bone and implanted porous hydroxyapatite (HAP) in cavities in the tibia. After surgery, we continued the protocols until the end of 60 days when the rats were euthanized, and the bones were collected. Results: The volume of bone formed around HAP in parietal defect and biomechanical findings were lower in animals receiving FE compared to CT. Conclusion: Prolonged use of phenobarbital interferes with bone repair after injury, decreasing the osseointegration of HAP implants and making bones less resistant.
\end{abstract}

Keywords: Durapatite; Osseointegration; Osteogenesis; Phenobarbital/adverse effects; Bone and bones/drug effects

\section{RESUMEN}

Objetivo: Evaluar los efectos morfológicos del tratamiento con fenobarbital, sobre la neoformación ósea y sobre la biomecánica ósea del hueso de ratas Wistar. Métodos: Fueron utilizadas diez ratas divididas en dos grupos: control (CT) y fenobarbital (FE). El grupo FE recibió dosis diarias de fenobarbital $0,035 \mathrm{ml} / \mathrm{kg}$ vía intramuscular, por 60 días. El grupo CT recibió la misma dosis y vía de administración de solución fisiológica $0,9 \%$. Después de 30 días, se realizó una falla ósea en el hueso parietal e implantó la hidroxiapatita porosa (HAP) en cavidades en las tibias. Después de las cirugías, se mantuvo los respectivos protocolos hasta completar 60 días y de ser eutanasiados, siendo recolectados los huesos. Resultados: El volumen de hueso formado alrededor HAP en la falla parietal y los hallazgos biomecánicos fueron menores en los animales del grupo FE en relación al CT. Conclusión: El uso prolongado del fenobarbital interfiere en la reparación ósea después de lesiones, disminuye la óseointegración de implantes de HAP y vuelve a los huesos menos resistentes.

Descriptores: Durapatita; Oseointegración; Osteogenésis; Fenobarbital/efectos adversos; Huesos/efectos de drogas

* Estudo realizado no Laboratório de Fitofármacos da Universidade de José do Rosário Vellano - UNIFENAS, Alfenas (MG), Brasil.

1 Acadêmicos do Curso de Enfermagem, Universidade José do Rosário Vellano - UNIFENAS, Alfenas (MG), Brasil.

2 Professores do Curso de Enfermagem, Universidade José do Rosário Vellano - UNIFENAS, Alfenas (MG), Brasil.

${ }^{3}$ Pós-graduação em Biologia Celular e Estadual do Instituto de Biologia, Universidade Estadual de Campinas, UNICAMP, Campinas (SP), Brasil. 


\section{INTRODUÇÃO}

Observações clínicas e experimentais destacam a ação nociva dos anticonvulsivantes sobre o tecido ósseo, bem como sobre o reparo deste. Adultos e crianças tratadas com anticonvulsivantes por tempo prolongado apresentam diminuição da densidade mineral óssea e redução do volume ósseo trabecular ${ }^{(1-3)}$, ocasionando osteoporose ${ }^{(4)}$, ou até mesmo manifestações mais severas, como a osteopenia e osteomalacia ${ }^{(5)}$. Aumenta os riscos de fraturas ósseas e dificulta o reparo ósseo pós-lesão ${ }^{(6)}$. Autores de estudos realizados ${ }^{(4)}$ concluíram que os anticonvulsivantes alteram a homeostasia do cálcio, sendo necessário o monitoramento do sistema esquelético de pacientes submetidos à terapia prolongada com esse medicamento ${ }^{(7)}$.

Autores ${ }^{(8)}$ estudaram os efeitos do fenobarbital sobre a calcificação do disco epifisário do rádio de ratos jovens, observando calcificação fraca e irregular nas extremidades distal do rádio.

A avaliação dos efeitos nocivos que o uso prolongado do Fenobarbital pode apresentar sobre o tecido ósseo torna-se importante quando considerada a difusão desse medicamento no tratamento da epilepsia, mesmo frente ao desenvolvimento de novas drogas, por se tratar de um medicamento completo, efetivo e de baixo custo, tornando-se, assim, de enorme valia a maior compreensão de como essa medicação pode afetar o tecido ósseo de seus usuários. Esse conhecimento é importante para a implementação da assistência de enfermagem, podendo orientar a tomada de medidas preventivas que amenizem possíveis aumentos de tais efeitos, como orientações de dietas adequadas que favoreçam o consumo de cálcio, amenizando possíveis alterações na homeostasia do cálcio acarretada pelo uso desta medicação e medidas de prevenção de quedas pela menor resistência óssea, consequência também de seu uso.

Perante o exposto, o presente estudo teve por objetivo investigar os efeitos morfológicos do tratamento prolongado com fenobarbital, sobre a neoformação óssea e sobre a biomecânica óssea do osso de ratos Wistar.

\section{MÉTODOS}

Protocolo Animal - Após aprovação pelo Comitê de Ética em Pesquisa da Universidade José do Rosário Vellano (UNIFENAS), Protocolo n ${ }^{\circ} 22 \mathrm{~A} / 2009$, realizouse este estudo no Laboratório de Fitofármacos da UNIFENAS, respeitando-se a Legislação Brasileira de Animais de Experimentação, regulamentada pela Lei Federal n. ${ }^{\circ}$ 6.638/79. Foram utilizados dez ratos machos (Rattus norvegicus) da linhagem Wistar, com 30 dias de vida, pesando $85 \pm 2 \mathrm{~g}$. Os animais foram encaminhados ao Laboratório de fitofármacos, tratados com água e ração ad libitum e mantidos com controle de temperatura a $25^{\circ} \mathrm{C}$ e $12 \mathrm{~h}$ no ciclo claro/ escuro, em caixas de polipropileno adequadas à sua manutenção. Os dez animais foram divididos em dois grupos experimentais $(n=5)$ : grupo CT (Controle) e grupo FE (Fenobarbital). Os animais do grupo FE receberam doses diárias de fenobarbital $0.035 \mathrm{ml} / \mathrm{kg}$ de peso do animal, administrado por via intramuscular (IM), por um período de 60 dias. O grupo CT recebeu a mesma dose e via de administração de solução fisiológica $0,9 \%$, mantendo o mesmo padrão de estresse entre os grupos.

Semanalmente, a pesagem dos animais e a mensuração do consumo sólido e líquido para calcular a ingestão calórica média foram realizadas.

Procedimento Cirúrgico - Os animais foram anestesiados com solução 1:1 de quetamina (Francotar ${ }^{\circledR}$ ) e cloridrato de xilazina (Virbaxyl ${ }^{\circledR} 2 \%$ ) na dose de 0,10 $\mathrm{ml} / 100 \mathrm{~g} \mathrm{IM}$, após 30 dias de administração do fenobarbital e da solução fisiológica $0,9 \%$. Tricotomia e incisão longitudinal na pele da calota craniana e da perna direita foram realizadas. O periósteo foi afastado, expondo a cortical óssea. No osso parietal direito, foi produzida uma cavidade de $5 \mathrm{~mm}$ com auxílio de um Punch trepano ${ }^{\circledR}$. Essa falha foi mantida aberta para verificação do osso neoformado ao término dos 30 dias de experimento. $\mathrm{Na}$ epífise proximal da tíbia direita, foi realizada outra falha de $3 \mathrm{~mm}$ e implantada a biocerâmica Hidroxiapatita Porosa (HAP). O periósteo no parietal e na tíbia foi reposicionado por meio da sutura de suas bordas com fio de seda 8.0, e a pele foi suturada com fio de algodão 4.0. A biocerâmica HAP foi produzida pelo Instituto de Química da Unicamp, apresentando 3 $\mathrm{mm}$ de diâmetro e $3 \mathrm{~mm}$ de comprimento. Todos os animais foram tratados com analgésico (dipirona sódica $500 \mathrm{mg} / \mathrm{mL}$ ) adicionado à água (ad libitum) na dose de $875 \mathrm{mg} / \mathrm{kg}$, por 48 horas. Após 24 horas da cirurgia, os animais deambulavam sem limitações significantes. Ao completar 60 dias de experimento, os animais sofreram eutanásia por meio de overdose anestésica, por via intraperitoneal (IP), utilizando-se xilazina/ ketamina $\left(\right.$ Francotar $^{\circledR}$, Virbaxyl $^{\circledR} 2 \%$ ) na concentração de $6-40 \mathrm{mg} / \mathrm{kg}$, respectivamente.

Processamento Histomorfométrico - O osso parietal direito e a tíbia direita depois de coletados foram fixados em formalina tamponada a $10 \%$ por 48 horas e descalcificados em solução de ácido fórmico, formol e citrato de sódio durante 15 dias. Em seguida, os ossos foram reduzidos e incluídos em parafina para cortes histológicos. Foram realizados cortes transversais semisseriados com 6 micrômetros de espessura, depositados em lâminas. Em seguida, foram corados com hematoxilina/eosina (HE) para análise morfológica ${ }^{(9)}$.

$\mathrm{O}$ volume de osso neoformado foi obtido com o auxílio de um retículo quadrilátero de 100 pontos acoplado à ocular do microscópio. Após a contagem dos pontos, foi utilizada a fórmula $\mathrm{Vv}_{\mathrm{v}}=\mathrm{Pp} / \mathrm{Pt}(\%)$, onde $\mathrm{V}_{\mathrm{V}}=$ densidade de volume ou volume relativo; $\mathrm{P}_{\mathrm{p}}$ $=$ quantidade de pontos sobre o osso neoformado; $\mathrm{P}_{\mathrm{T}}=$ número total de pontos do sistema ${ }^{(10)}$.

Teste mecânico dos fêmures - Para a realização do teste mecânico, os fêmures esquerdos dos animais foram coletados, limpos e acondicionados em gaze embebida em solução fisiológica $(0,9 \%)$ e armazenados em freezer $\left(-20^{\circ} \mathrm{C}\right)$ até o dia anterior ao ensaio. Os fêmures foram submetidos a teste mecânico de 
resistência no Laboratório de Propriedades Mecânicas da Faculdade de Engenharia Mecânica da UNICAMP. O ensaio mecânico foi realizado em um módulo de flexão de três pontos, MTS TestStar II, utilizando um célula de carga de $100 \mathrm{Kgf}$, a uma velocidade de $1.3 \mathrm{~mm} / \mathrm{min}$. A distância entre as duas extremidades ósseas foi de $50 \mathrm{~mm}$, e, para se obter o valor da resistência, uma carga foi aplicada no terço médio do osso (diáfise) por meio de uma ponta, acoplada a uma máquina de ensaio universal ${ }^{(9)}$. A força máxima necessária para a ruptura completa dos fêmures foi obtida, após uma célula de carga registrada pelo Módulo de Flexão MTS em Newton (N).

Análise Estatística - O consumo diário de ração e do líquido por animal em cada grupo foram calculados por meio da obtenção da média e do desvio-padrão de cada um deles. O percentual de ganho de massa corporal dos animais de cada grupo foi verificado por intermédio da aplicação do teste $T$ de Stundent, para uma melhor comparação entre os grupos. A técnica de Anova (Análise de Variância) foi utilizada para análise morfométrica macroscópica e microscópica. A comparação entre os grupos foi realizada como o auxílio do Teste Tukey-Kramer, programa Instat for Windows, comparando as médias obtidas.

\section{RESULTADOS}

O consumo líquido e sólido foi satisfatório entre os grupos, porém os animais do grupo FE apresentaram menor ingesta sólida, quando comparados com os animais dos grupos CT (Tabela 1). Durante o experimento, todos os animais ganharam peso (Tabela 1).

Os resultados morfométricos demonstraram que os animais do grupo FE apresentaram menor volume de osso neoformado ao redor dos implantes de HAP em relação ao grupo CT (Figura 1 e Tabela 1). $\mathrm{Na}$ falha óssea realizada no osso parietal, também foi observado menor volume de osso neoformado nos animais do grupo FE (Figura 2 e Tabela 1).
Tabela 1 - Valores da média e desvio padrão do ganho de peso ("P) semanal, do consumo líquido e sólido diário, do volume de osso neoformado ao redor do implante de HAP nas tíbias (ON-T), do reparo da falha do osso parietal (ON-P), da força máxima (FMáx), do deslocamento máximo (DMáx) e da rigidez (Rig) dos ossos dos animais do grupo CT e FE

\begin{tabular}{lcc}
\hline Variáveis an alisadas & CT & FE \\
\hline $\mathrm{N}$ & 05 & 05 \\
$\Lambda \mathrm{P}(\mathrm{g})$ & $287,00 \pm 2,10^{\mathrm{a}}$ & $286,00 \pm 1,00^{\mathrm{a}}$ \\
Líquida $(\mathrm{mL})$ & $41,00 \pm 0,70^{\mathrm{a}}$ & $41,00 \pm 0,30^{\mathrm{a}}$ \\
Sólida $(\mathrm{g})$ & $53,02 \pm 1,00^{\mathrm{a}}$ & $49,00 \pm 0,60^{\mathrm{b}}$ \\
ON-T $(\%)$ & $37,00 \pm 3,70^{\mathrm{a}}$ & $25,00 \pm 0,50^{\mathrm{b}}$ \\
ON-P (\%) & $37,20 \pm 3,70^{\mathrm{a}}$ & $25,00 \pm 0,50^{\mathrm{b}}$ \\
FMáx $(\mathrm{N})$ & $119,0 \pm 2,07 \mathrm{a}$ & $84,0 \pm 5,10 \mathrm{~b}$ \\
DMáx $(\mathrm{mm})$ & $37,20 \pm 3.70^{\mathrm{a}}$ & $25,00 \pm 0,50^{\mathrm{b}}$ \\
Rig $(\mathrm{N} / \mathrm{mm})$ & $119,0 \pm 2,07^{\mathrm{a}}$ & $96,00 \pm 3,10^{\mathrm{b}}$ \\
\hline
\end{tabular}

${ }^{*} \mathrm{p}<0,005$ comparado com CT. Dados expressos em média \pm desvio-padrão, letras iguais sem diferença estatística.

$\mathrm{Na}$ região onde foi implantada a HAP, não foram observadas ulcerações ou complicações no processo de cicatrização da pele dos animais do grupo CT e FE. Em todos os animais, não se evidenciou processo inflamatório e/ou infeccioso no local de implantação da HAP. Aparentemente, a HAP manteve-se no interior da cavidade óssea, sem a ocorrência de migração de grânulos para outros locais fora da área de implantação. Os cortes histológicos do sítio de implantação de HAP nas tíbias dos animais do grupo FE demonstraram osso neoformado ao redor do implante, porém a reparação óssea caracterizou-se por uma grande quantidade de osso imaturo que facilmente se distinguia das demais áreas da tíbia (Tabela 1 e Figura 1). A falha do osso parietal dos animais do grupo CT foi praticamente reparada, diferentemente da achada no grupo FE, que ainda exibia atividade osteogenia e nítida distância entre as bordas da falha óssea (Tabela 1 e Figura 2).

\section{DISCUSSÃO}
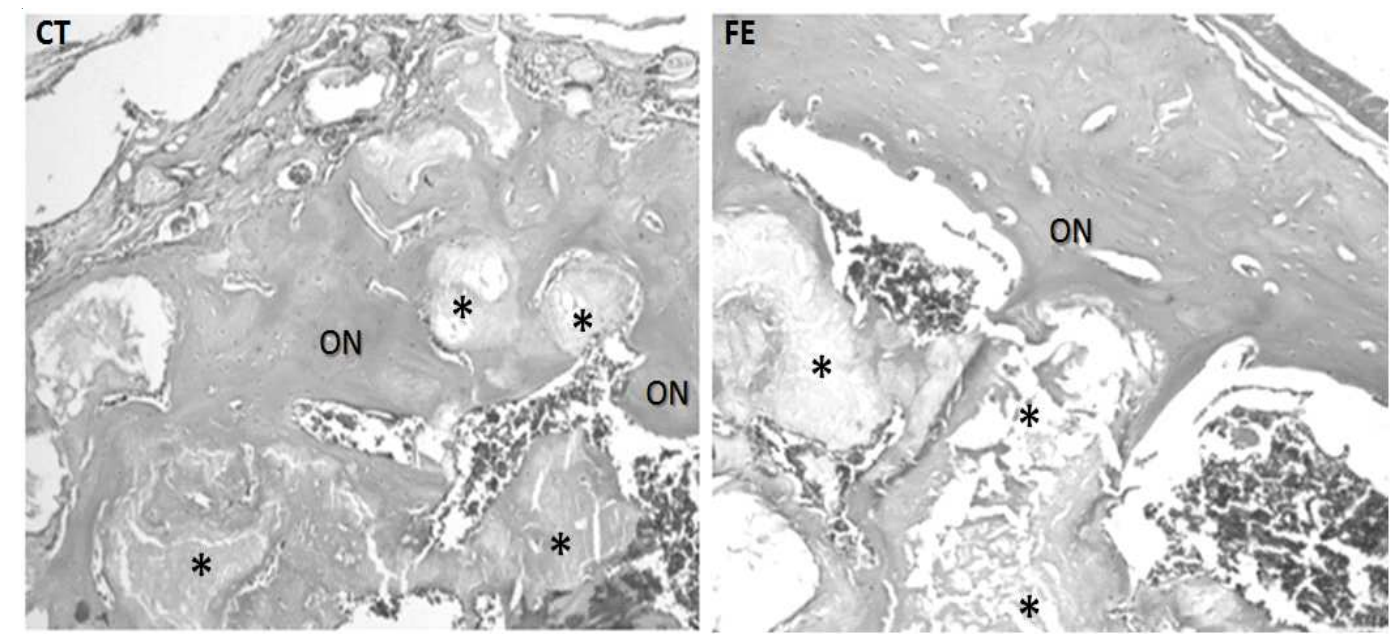

Figura 1 - Fotomicrografia de corte transversal da tíbia do grupo CT e FE. Comparação do osso neoformado $(\mathrm{ON})$ ao redor do implante de $\mathrm{HAP}(*)$. 

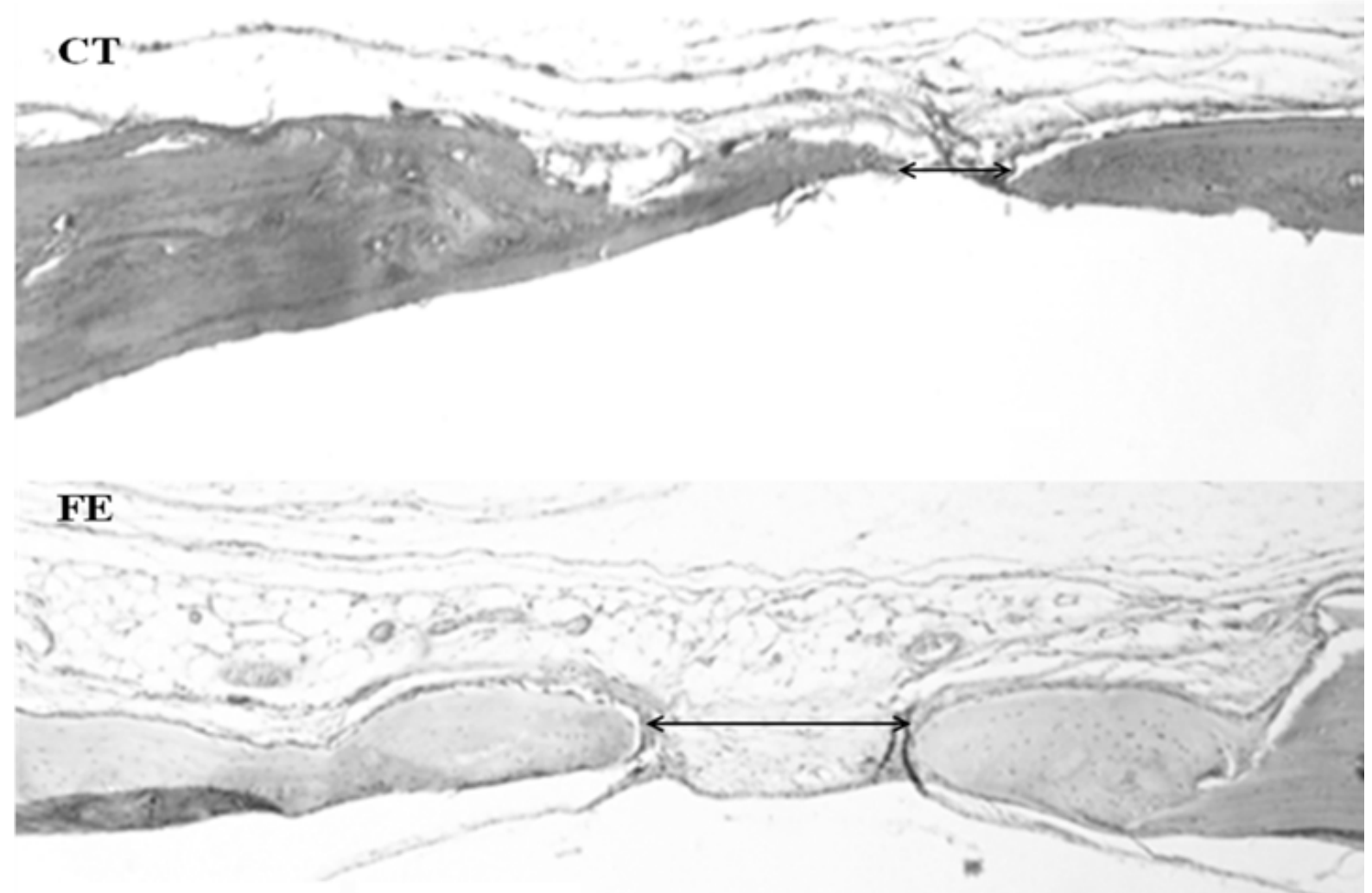

Figura 2 - Fotomicrografia frontal do osso parietal exibindo menor neoformação na falha óssea dos animais do grupo FE em comparação com os do grupo CT. (HE 40X).

O presente estudo demonstrou que todos os animais, ao longo do experimento, ganharam peso. O uso crônico do fenobarbital não inferiu no consumo líquido dos animais, quando comparado ao grupo controle. Entretanto, diminuiu a quantidade da dieta sólida ingerida pelo grupo FE, quando comparado com o grupo CT.

Para autores ${ }^{(11)}$, os experimentos envolvendo o uso prolongado de drogas necessita de uma atenção especial referente ao estado nutricional dos animais, pois as variações no consumo de dieta sólida e líquida podem provocar modificações nas respostas biológicas dos animais em experimentação. O consumo de ingesta líquida e sólida, preconizada para manter o estado nutricional adequado dos ratos e evitar a desnutrição e a desidratação, é de 15 a $80 \mathrm{ml}$ de água e de $25 \mathrm{~g}$ de ração ao dia ${ }^{(12-13)}$. Nossos resultados mostraram que as alterações ósseas observadas no grupo FE não foram decorrentes da desnutrição proteica ou desidratação, pois todos os animais dos grupos estudados ganharam peso durante o experimento, e a ingestão sólida e líquida permaneceu dentro dos padrões preconizados. As diferenças encontradas na neoformação óssea ao redor do implante na tíbia, no reparo da falha óssea no parietal direito e na propriedade estrutural óssea (força máxima) entre os grupos, devem-se aos efeitos do uso crônico do fenobarbital, não sendo decorrentes de um quadro de desnutrição.

Estudos demonstram que o uso de agentes anticonvulsivantes afeta o tecido ósseo, dificultando os processos de reparo e de remodelamento ósseo ${ }^{(14)}$. Autores $^{(7)}$, por exemplo, realizaram um estudo clínico com 71 pacientes, 42 adultos e 29 crianças/adolescentes, sendo todos usuários de anticonvulsivantes por no mínimo três meses. Avaliaram a densidade mineral óssea (DMO) e os níveis séricos de 25 hidroxi-vitamina D (25-OHD). Concluíram, pois, que grande parte da amostra estudada apresentava histórico de uso de fenobarbital e que, entre o grupo, 50\% apresentavam alterações na DMO e nos níveis da 25-OHD. No entanto, são escassos os estudos que associam o uso do fenobarbital com a osseointegração de implantes de HAP com a biomecânica óssea.

No presente estudo, a análise histomorfométrica demonstrou que, no sítio de implantação da HAP, não foram observados sinais de rejeição, presença de resposta inflamatória crônica ou formação de camada de tecido fibroso entre o osso neoformado e a hidroxiapatita. Nos dois grupos (CT e FE), o osso neoformado encontrou-se em contato direto com os blocos de HAP, estando o osso neoformado no grupo CT maturo e, no grupo FE, variando em partes maturas e imaturas. A alteração mais importante observada referiu-se ao menor volume de osso encontrado ao redor dos implantes de HAP nos animais do grupo FE, quando comparados aos do grupo CT. Na falha óssea, os achados foram semelhantes, sem sinais patológicos e com o volume neoformado no grupo FE inferior ao do grupo CT. 
Estudos clínicos e experimentais demonstram que os anticonvulsivantes causam alterações no metabolismo da vitamina $\mathrm{D}$ e, consequentemente, no osso ${ }^{(15-16)}$. A diminuição da vitamina $\mathrm{D}$, hipovitaminose $\mathrm{D}$, acarreta inúmeras alterações no metabolismo ósseo, uma vez que a vitamina $\mathrm{D}$ auxilia na manutenção da massa óssea ${ }^{(17)}$, mobiliza cálcio do osso para a circulação, participa da maturação de colágeno ${ }^{(18)}$ e estimula a formação de osteocalcina, osteopantina e fosfatase alcalina ${ }^{(19)}$. Entre os anticonvulsivantes que interferem no metabolismo da vitamina $\mathrm{D}$, destaca-se o fenobarbital. Essa interferência baseia-se na inibição da enzima fosfatase alcalina e na diminuição da quantidade disponível do mineral para a formação óssea ${ }^{(20)}$. O volume de osso observado na falha no parietal direito foi menor nos animais do grupo FE, demonstrando uma diminuição da osteogênese.

Segundo autores ${ }^{(5)}$, o risco de osteoporose e osteopenia é aumentado em adultos usuários de fenobarbital, uma vez que o medicamento altera o metabolismo ósseo e diminui a densidade mineral óssea, propiciando fraturas ósseas. Os parâmetros analisados na biomecânica são significativos, pois ajudam a caracterizar um elemento biológico que tem grande importância na absorção, na transmissão e na

\section{REFERÊNCIAS}

1. Pastore ME, Ofuchi AS, Nishiyama P. Monitorização terapêutica de fenobarbital. Acta Sci Health Sci. 2007; 29(2):125-31.

2. Silva HT, Hartmann AA. A relação do uso crônico de fenobarbital com áreas potencialmente pré-neoplásicas em fígado de ratos. Arq Gastroenterol. 2006; 43(2):121-4.

3. Chung S, Ahn C. Effects of anti-epileptic drug therapy on bone mineral density in ambulatory epileptic children. Brain Dev. 1994; 16(5):382-5.

4. Kruse K, Bartels H, Ziegler R, Dreller E, Kracht U. Parathyroid function and serum calcitonin in children receiving anticonvulsant drugs. Eur J Pediatr. 1980; 133(2):151-6.

5. Pack AM, Morrell MJ. Adverse effects of antiepileptic drugs on bone structure: epidemiology, mechanisms, and therapeutic implications. CNS Drugs. 2001; 15(8):633-42.

6. Mascarenhas NM, Ideriha NM, Orsi AM. Alguns eventos morfológicos do processo de reparo de falha óssea diafisária no rádio esquerdo de ratos tratados com fenobarbital. Braz J Vet Res Anim Sci. 1999; 36(4):188-193.

7. Farhat G, Yamout B, Mikati MA, Demirjian S, Sawaya R, El-Hajj Fuleihan G. Effect of antiepileptic drugs on bone density in ambulatory patients. Neurology. 2002. 58(9):1348-53.

8. Gascon-Barré M, Côté MG. Influence of phenobarbital and diphenylhydantoin on the healing of rickets in the rat. Calcif'Tissue Res. 1978; 25(1):93-7.

9. Soares EV, Fvaro WJ, Cagnon VH, Bertran CA, Camilli JA. Effects of alcohol and nicotine on the mechanical resistance of bone and bone neoformation around hydroxyapatite implants. J Bone Miner Metab. 2010; 28(1):101-7.

10. Mandarin-de-Lacerda CA. What is the interest of normal and pathological morphological research to be quantitative? The exemple of the stereology. Braz J Morphol Sci. 1999; 16(2):131-9. resistência a esforços físicos. O ensaio biomecânico demonstrou diminuição da força máxima necessária para a ruptura completa dos fêmures dos animais do grupo FE; evidenciou também neste grupo a diminuição da rigidez (Stiffness), deixando os ossos com mais susceptibilidade às fraturas.

Estudos demonstram que a osteoporose em pacientes usuários de anticonvulsivante está associada à alteração no metabolismo da vitamina $\mathrm{D}$, à diminuição dos níveis de cálcio, à redução da $\mathrm{DMO}$ e à perda óssea ${ }^{(14,18)}$. Os resultados deste estudo demonstram que, em todas as variáveis analisadas, volume de osso neoformado e biomecânica óssea, os animais do grupo FE apresentaram comprometimentos ósseos maiores.

\section{CONCLUSÃO}

Os achados do presente estudo demonstram que o uso do fenobarbital interfere no reparo ósseo após lesões, diminui a osseointegração de implantes de HAP e torna ossos menos resistentes.

11. Weisbroth SH, Paganelli RG, Salvia M. Evalution of a disposable system during shipment of laboratory rats and mice. Lab anim Sci. 1977; 27(2):186-94.

12. Svendsen P, Hau J. Handbook of laboratory animal science. CRC Press, Boca Raton: CRC Press; 1984.

13. Palencia G, Teixeira F, Ortiz A, Perez R, Rios C, Sotelo J. Detrimental effects of mainutrition on the damage inducedby alcoholism: a study of animal models that simulate chronic alcoholism and malnutrition of larger human groups. J Stud Alcohol. 1994; 55(1):113-20.

14. Verrotti A, Coppola G, Parisi P, Mohn A, Chiarelli F. Bone and calcium metabolism and antiepileptic drugs. Clin Neurol Neurosurg. 2010;112(1):1-10.

15. Parara EM, Galanopoulou PB, Rallis G, Vairaktaris E, Tesseromatis CP. Mandibular bone density and calcium content affected by long-term anticonvulsant treatment in rats. J Musculoskelet Neuronal Interact. 2009; 9(1):32-7.

16. Nilsson OS, Lindholm TS, Elmstedt E, Lindbäck A, Lindholm TC. Fracture incidence and bone disease in epileptics receiving long-term anticonvulsant drug treatment. Arch Orthop Trauma Surg. 1986; 105(3):146-9.

17. Fraser WD. Hyperparathyroidism. Lancet, 2009; 374(9684):145-58.

18. Lee RH, Lyles KW, Colón-Emeric C. A review of the effect of anticonvulsant medications on bone mineral density and fracture risk. Am J Geriatr Pharmacother. 2010; 8(1):3446.

19. Bouillon R, Okamura WH, Norman AW. Structurefunction relationships in the vitamin $\mathrm{D}$ endocrine system. Endocr Rev. 1995;16(2):200-57.

20. Broulik P, Kragstrup J, Mosekilde L, Melsen F. Osteon cross-sectional size in the iliac crest: variation in normals and patients with osteoporosis, hyperparathyroidism, acromegaly, hypothyroidism and treated epilepsia. Acta Pathol Microbiol Immunol Scand A. 1982; 90(5):339-44. 